\title{
The observational, cross-sectional study of drug utilization $90 \%$ and use of dipeptidyl peptidase- 4 inhibitor in the patients with type 2 diabetes mellitus
}

\author{
Prashant P. Shivgunde ${ }^{1 *}$, Shantanu R. Joshi ${ }^{2}$, Archana D. Kodilkar ${ }^{1}$
}

\begin{abstract}
${ }^{1}$ Department of University
Research, Maharashtra

University of Health Sciences

(MUHS), Mhasrul, Vani-

Dindori Road, Nashik,

Maharashtra, India

${ }^{2}$ Global Herbs Pharmaceuticals,

Pune-Satara Road, Pune,

Maharashtra, India

Received: 28 September 2019

Revised: 11 October 2019

Accepted: 14 October 2019

*Correspondence to:

Dr. Prashant P. Shivgunde,

Email: prashantshivgunde@ gmail.com
\end{abstract}

Copyright: (C) the author(s), publisher and licensee Medip Academy. This is an openaccess article distributed under the terms of the Creative Commons Attribution NonCommercial License, which permits unrestricted noncommercial use, distribution, and reproduction in any medium, provided the original work is properly cited.

\begin{abstract}
Background: Diabetes is a chronic metabolic disease which affects the quality of life. It leads to multiple complications due to metabolic involvement. Out of multiple drugs used to treat diabetes, dipeptidyl peptidase 4 (DPP-4) inhibitors are comparatively new drugs used for type-2-diabetes mellitus (DM) treatment. This study aimed to find out the drug utilization (DU) $90 \%$ and use of DPP-4 inhibitors in patients with type-2-DM.

Methods: A prospective, cross-sectional, observational study was conducted at a private healthcare clinic of an endocrinologist in Nashik. Type-2-DM patients of both sexes were selected and a total of 199 patients were enrolled in the study. The consented patients were interviewed and prescription copies were collected. After studying them; statistical analysis was done and results and conclusions were drawn.

Results: Out of total prescribed drugs, $58.77 \%$ of drugs were anti-diabetics. It was observed that the biguanides were most frequently $(25.32 \%)$ prescribed while the least prescribed drugs were meglitinide analogues $(0.08 \%)$. Most commonly utilized anti-diabetic found to be metformin. Vildagliptin $50 \mathrm{mg}$ is the most commonly prescribed drug from DPP-4 inhibitors. Most of the drugs from the DPP-4 inhibitor group came under DU90\%.

Conclusions: DPP-4 inhibitors are showing wide acceptability by endocrinologists for type-2-DM management, according to this study. Performing repetitive drug utilization pattern study and circulation of standard treatment guidelines to practising physicians can be required. To emphasize the point on generic prescription, more awareness should be created. So that these can responses to further cost-effective and rational prescribing practices.
\end{abstract}

Keywords: Diabetes, DPP-4 inhibitors, Drug utilization study, Daily defined dose, DU $90 \%$

\section{INTRODUCTION}

The irrational use of drugs is a major problem of a present-day medical practice and its consequences include ineffective treatment, unnecessary prescription of drugs, development of resistance to antibiotics, adverse effects and economic burden on patients and society. In spite of extensive programs on the rational use of drugs and the essential drug list (EDL) of World Health Organization (WHO), which are being promoted by various national and international agencies working on the health sector, an irrational prescription is still a common practice. There is a need for mass awareness amongst physicians and consumers about the concept of essential medicines, advantages of generic drug prescription and use of rational combinations. ${ }^{1}$ Drug utilization (DU) research was defined by WHO in 1997 as "The marketing, distribution, prescription, and use of drugs in a society, with special emphasis on the resulting medical, social, and economic consequences". ${ }^{2}$

DU $90 \%$ segment reflects the number of drugs that account for $90 \%$ of drug prescriptions and adherence to the local or national prescription guidelines to obtain a 
rough estimate of the quality of prescribing. DU $90 \%$ calculated for the description of the drug use patterns. The rationale behind the development of DU $90 \%$ rest on an assumption that a low number of products prescribed is associated with the more rational prescribing practice. DU $90 \%$ study provides a basis for areas needs to be analysed in detail for assessing the quality of prescribing. ${ }^{2}$

Diabetes is a chronic metabolic disease which affects the quality of life. It leads to multiple complications due to metabolic involvement. Diabetes has become one of the major cause of death. Out of two forms of diabetes, one is the 'non-insulin dependent diabetes mellitus' i.e. type-2diabetes mellitus (DM). Oral hypoglycaemic agents i.e. anti-diabetic drugs acting through different pharmacological pathway are majorly used in the management of type-2-DM. This study involves a drug utilization analysis for them.

Sulfonylurea, biaguanides, meglitinide derivatives, thiazolidinedione, dipeptidyl peptidase 4 (DPP-4) inhibitors, and alpha-glucosidase inhibitors, etc. are the group of drugs used to treat type-2-DM as said above. Out of which DPP-4 inhibitors are comparatively new drugs. ${ }^{3,4}$ DPP-4 is an enzyme which is accountable for degradation of incretins like glucagon-like peptide-1 (GLP-1) and glucose-dependent insulinotropic polypeptide (GIP). Food intake responses to glucose release which leads to the secretion of the incretins. These incretins stimulate the pancreas and more insulin will be secreted. So, it leads to blood sugar level control. ${ }^{5}$

Possibility of sudden hypoglycaemia is low with DPP-4 inhibitors. In one way they are safer in developing hypoglycaemia because their effect starts after incretins secretion in response to a rise in blood glucose. DPP-4 inhibitor is one of the important and comparatively new in type-2-DM management. It was also noted in many multicentre studies that they are safe and effective in a real-world population. ${ }^{6,7}$ This research aims to study DU $90 \%$ and drug use pattern in type-2-DM patients with specific reference to the role of DPP-4 inhibitors. This will be helpful to formulate the role of DPP-4 inhibitors in type-2-DM management and promote rational use by calculating DU90\%.

\section{METHODS}

A prospective, cross-sectional, observational study was conducted at the outpatient department (OPD) of Dr. Buva's Hormocare Clinic (the private healthcare clinic of an endocrinologist) in Nashik from December 2017 to February 2018, after approval from the local ethics committee and permission at the study site. The study was conducted in compliance with ICH-GCP guidelines, schedule Y, WHO guidelines and Indian Council of Medical Research (ICMR) guidelines. Considering the prevalence rate of $15 \%$ for type-2-DM, the total sample size calculated was 196. The convenient sampling technique was used in this study.

The patient enrolment was done as per the inclusion and exclusion criteria. Patients of 18 years old and above of either sex with type-2-DM who received anti-diabetic medicine at the OPD were selected. Patients in the inpatient department (IPD), patients those who were unable to comply due to mental retardation and those who were not willing to give informed consent were excluded. Before enrolment signed, dated and written informed consent was taken from the patients after providing information about the study with proper explanation. Thereafter the patients were interviewed and prescription copies were collected. These prescriptions were studied; defined daily dose (DDD)\% and DU90\% were calculated. After statistical analysis; results and conclusions were drawn.

\section{Data analysis}

The Statistical Package for Social Sciences (IBM SPSS Statistics for window, NY: IBM Corp.) and Microsoft Excel 2010 were used for the analysis of data. Drug utilization parameters were analyzed as follows;

- DDD/1000/day $=[$ Total no. of dosage units prescribed $\times$ Strength of each dose unit $\times 1000$ ]/ $[$ DDD $($ ATC $) \times$ Duration of study in weeks $\times$ Total sample size]

- $\mathrm{DDD} \%=[\mathrm{DDD} / 1000 /$ day of particular drug x 100]/ [Sum of DDD/1000/day total drugs]

- DU $90 \%$ was calculated by addition of DDD percentages of the drugs involved.

Descriptive statistics such as percentages were also measured. Tabulation, graph, and diagrams were used to present the data.

\section{RESULTS}

According to the statistical calculation of sample size, a minimum of 196 patients of type-2-DM could be taken. In the pre-screening, the number of potentially eligible patients were 233 whereas the number of confirmed eligible patients included in the study was 199. Out of which $104(52.26 \%)$ were male while $95(47.74 \%)$ were female. Out of total prescribed drugs, $58.77 \%$ were antidiabetic drugs. Some of the other demographic parameters and the prescription indices are mentioned in Table 1 and Table 2.

From all the anti-diabetic group of drugs, Biguanides were highly prescribed $(25.32 \%)$. DPP-4 inhibitor was the third highly prescribed anti-diabetic group of drugs followed by sulfonylureas $(12.78 \%)$ and then DPP-4 inhibitors $(9.78 \%)$. The least prescribed drugs were from the meglitinide analogues group $(0.08 \%)$ (Figure 2$)$. 
Table 1: Details of demographic parameters.

\begin{tabular}{|l|l|}
\hline Demographic profile & $\begin{array}{l}\text { No. of } \\
\text { patients }\end{array}$ \\
\hline Total sample size & 199 \\
\hline Male & 104 \\
\hline Female & 95 \\
\hline Patients with type 2 DM only & 111 \\
\hline $\begin{array}{l}\text { Patients with type 2 DM and } \\
\text { cardiovascular diseases }\end{array}$ & 45 \\
\hline $\begin{array}{l}\text { Patients with type 2 DM and thyroid } \\
\text { disorders }\end{array}$ & 28 \\
\hline $\begin{array}{l}\text { Patients with type 2 DM, cardiovascular } \\
\text { diseases and thyroid disorders }\end{array}$ & 15 \\
\hline
\end{tabular}

Table 2: Details of prescription indices.

\begin{tabular}{|ll|}
\hline Prescription indices & $\begin{array}{l}\text { No. of } \\
\text { drugs }\end{array}$ \\
\hline Total number of drugs prescribed & 93 \\
\hline Drugs prescribed for type-2-DM & 54 \\
\hline $\begin{array}{l}\text { Drugs prescribed for co-morbid } \\
\text { conditions }\end{array}$ & 39 \\
\hline Total number of dosages prescribed & 1236 \\
\hline $\begin{array}{l}\text { Number of dosages per prescription } \\
\text { (average) }\end{array}$ & 6.21 \\
\hline $\begin{array}{l}\text { Total number of combinations } \\
\text { prescribed }\end{array}$ & $\begin{array}{l}814 \\
\text { (average } \\
4.09)\end{array}$ \\
\hline
\end{tabular}

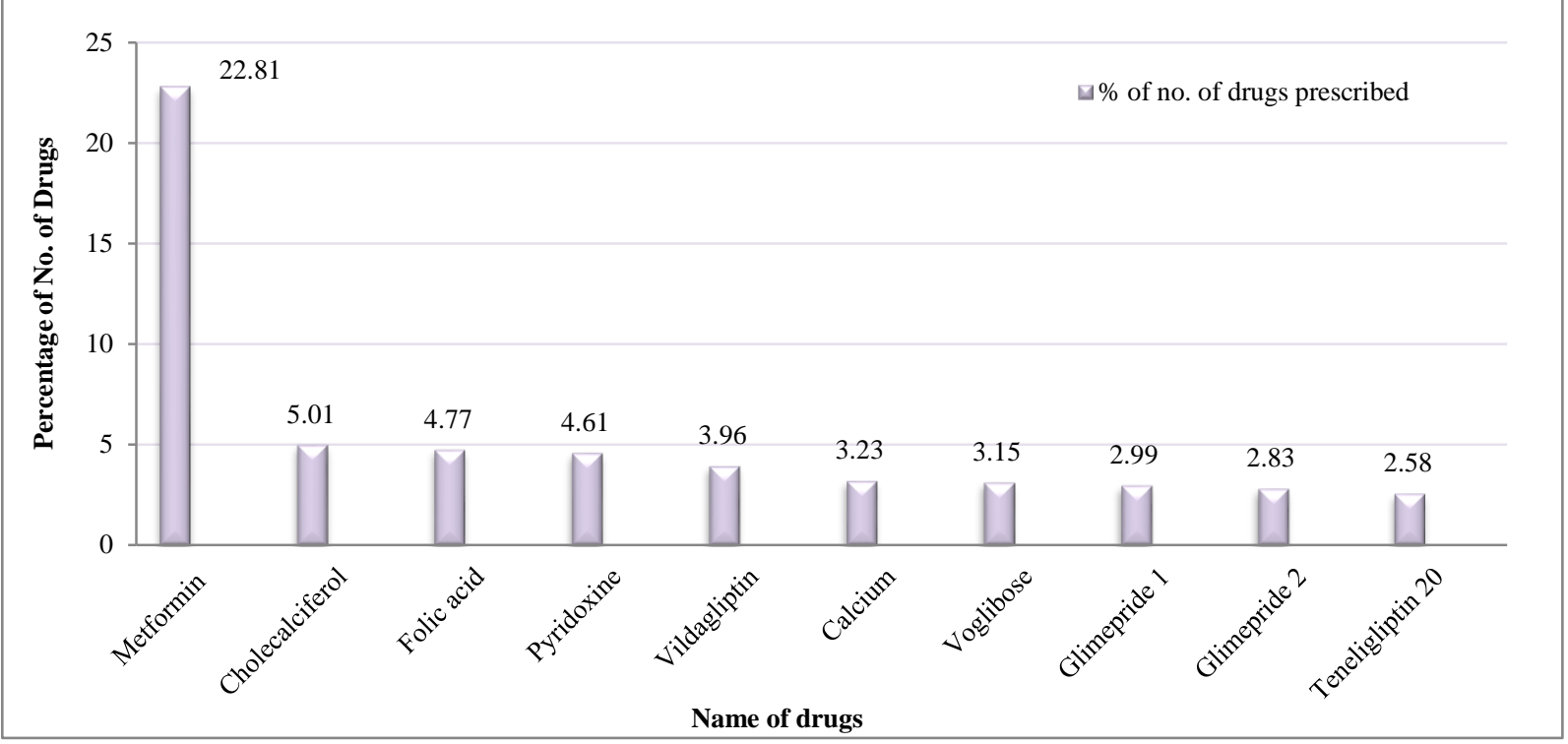

Figure 1: Percentage distribution of top 10 prescribed drugs in type-2-DM.

All coloured bars indicate the percentage number of drugs prescribed. X-axis: Name of drugs; Y-axis: Percentage number of drugs.

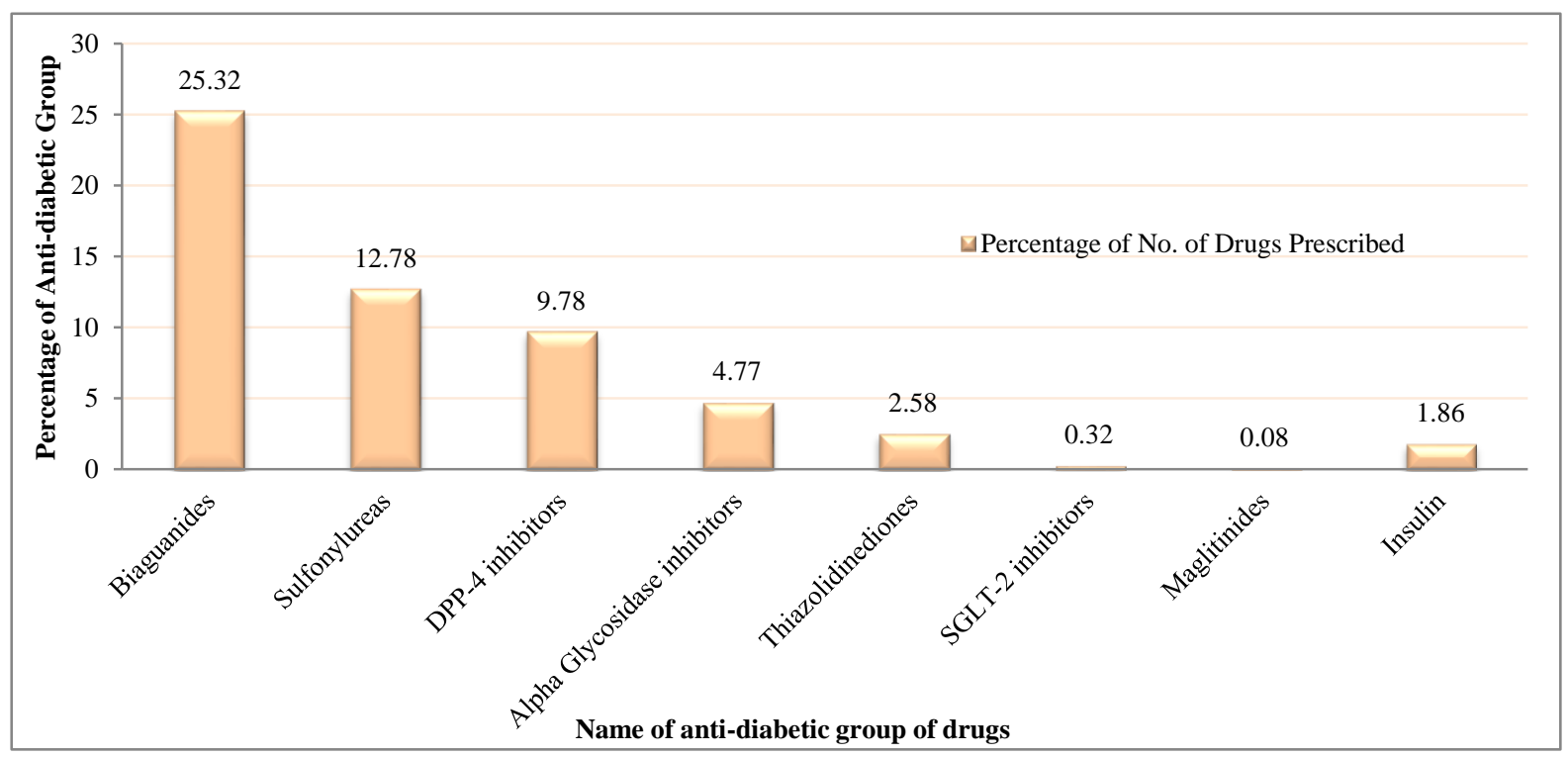

Figure 2: Percentage distribution of groups of anti-diabetic drugs.

All coloured bars indicate the Percentage of a group of antidiabetic drugs prescribed. X-axis: Name of an anti-diabetic group of drugs; Y-axis: Percentage of anti-diabetic group. 


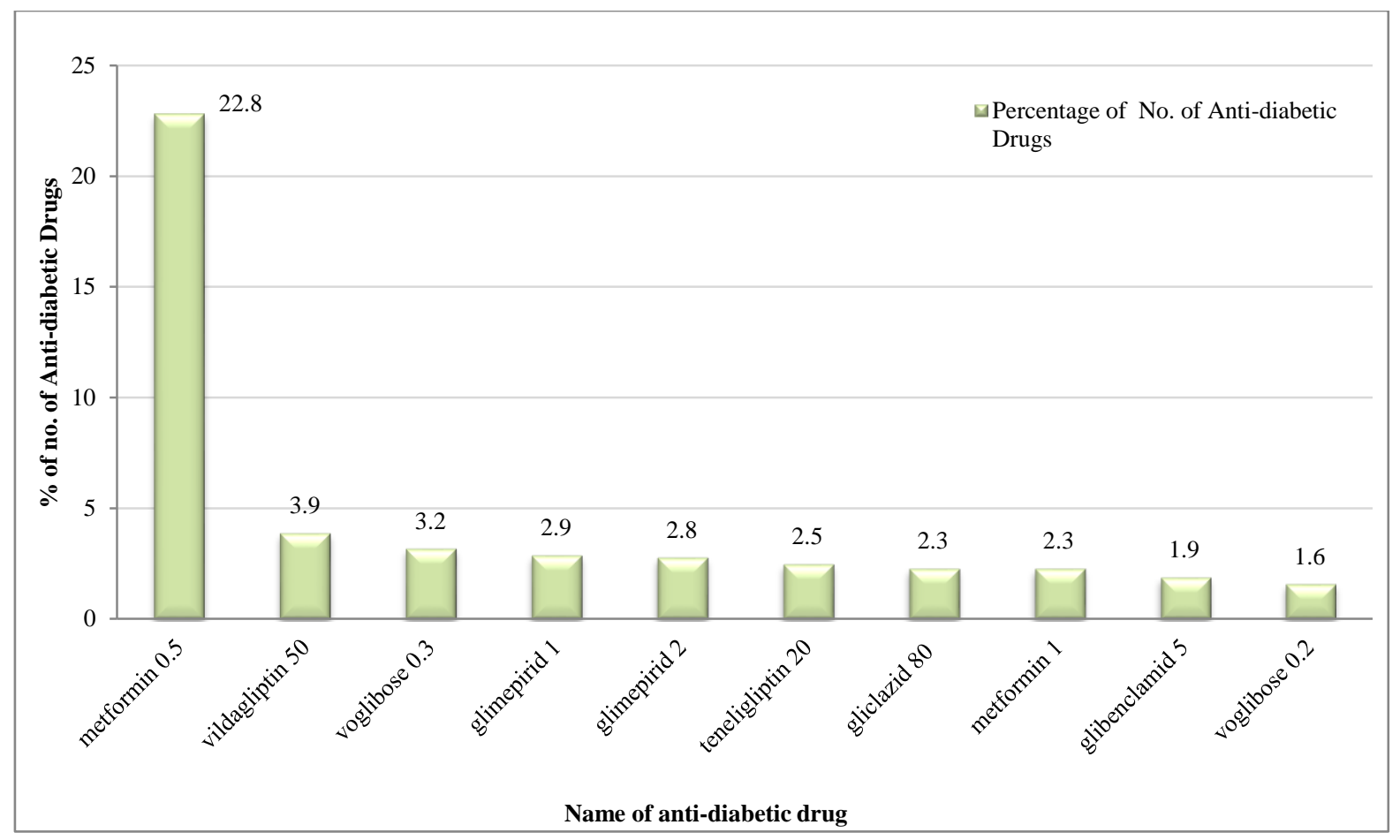

Figure 3: Percentage distribution of top $\mathbf{1 0}$ prescribed anti-diabetic drugs.

All coloured bars indicate the percentage of top 10 anti-diabetic drugs prescribed. X-axis: Name of anti-diabetic drug; Y-axis: Percentage of anti-diabetic drugs.

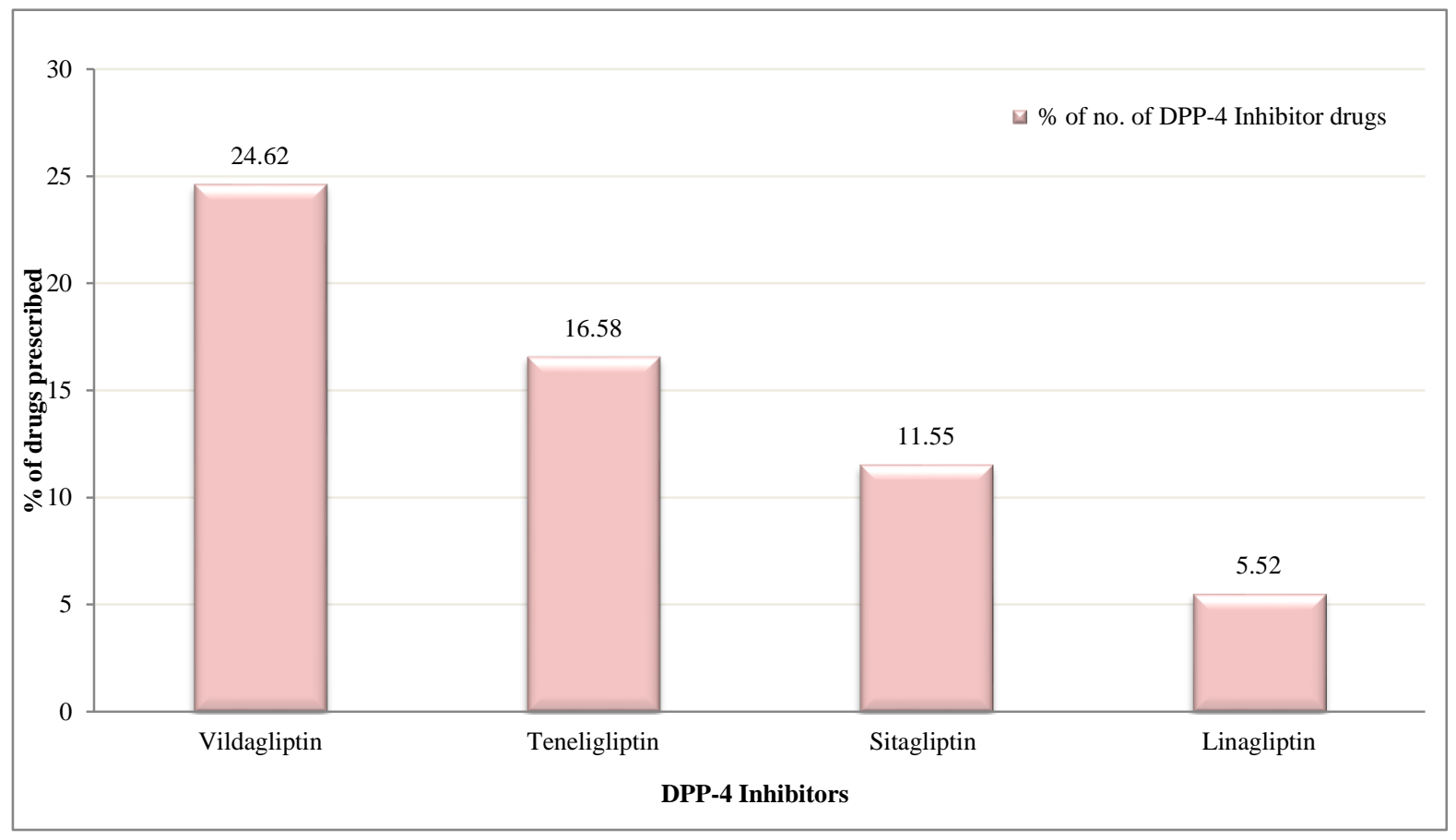

Figure 4: Percentage distribution of different DPP-4 inhibitors prescribed in type-2-DM.

All coloured bars indicate the percentage of different DPP-4 Inhibitor drugs prescribed. X-axis: DPP-4 Inhibitors; Y-axis: Percentage of drugs prescribed.

Metformin $0.5(22.8 \%)$ was highly prescribed the oral hypoglycaemic drug. Vildagliptin 50 (3.9) was the second most prescribed while teneligliptin 20 (2.5) was the sixth most prescribed anti-diabetics from DPP-4 inhibitors class (Figure 3).
'Vildagliptin 50' was the most prescribed DPP-4 inhibitor drug. (24.62\%) vildagliptin was prescribed to 49 patients amongst all while teneligliptin, sitagliptin, and linagliptin were prescribed to 33,23 and 11 patients respectively (Figure 4). 
Table 3: Details of drug utilization parameters and DU90\% for drugs used in type-2-DM management.

\begin{tabular}{|c|c|c|c|c|c|}
\hline Sr.no. & Drug & ATC Code & $\begin{array}{l}\text { Total no. of dosage } \\
\text { units prescribed }\end{array}$ & DDD/1000/Day & DDD\% \\
\hline 1 & Cholecalciferol 1000 & A11CC05 & 62 & 48.68090452 & 9.785241383 \\
\hline 2 & Metformin 0.5 & A10BA02 & 282 & 44.2839196 & 8.901413129 \\
\hline 3 & Insulin human & $\mathrm{A} 10 \mathrm{AB} 01$ & 8 & 30.65326633 & 6.161545542 \\
\hline 4 & Calcium & A12AA20 & 40 & 25.12562814 & 5.050447165 \\
\hline 5 & Gliclazid 80 & A10BB09 & 29 & 24.2881072 & 4.882098926 \\
\hline 6 & Glimepirid 2 & A10BB12 & 35 & 21.98492462 & 4.41914127 \\
\hline 7 & Cholecalciferol 2000 & $\mathrm{~A} 11 \mathrm{CC} 05$ & 13 & 20.41457286 & 4.103488322 \\
\hline 8 & Rabeprazole & A02BC04 & 16 & 20.10050251 & 4.040357732 \\
\hline 9 & Teneligliptin 20 & NA & 32 & 20.10050251 & 4.040357732 \\
\hline 10 & Talmisartan 40 & C09CA07 & 26 & 16.33165829 & 3.282790657 \\
\hline 11 & Vildagliptin 50 & $\mathrm{~A} 10 \mathrm{BH} 02$ & 49 & 15.38944724 & 3.093398889 \\
\hline 12 & Voglibose 0.3 & A10BF03 & 39 & 12.24874372 & 2.462092993 \\
\hline 13 & Glimepirid 1 & A10BB12 & 37 & 11.62060302 & 2.335831814 \\
\hline 14 & Insulin mixtard & A10AE56 & 6 & 9.422110553 & 1.893917687 \\
\hline 15 & Metformin 1 & A10BA02 & 28 & 8.793969849 & 1.767656508 \\
\hline 16 & Amlodipin 5 & C08CA01 & 13 & 8.165829146 & 1.641395329 \\
\hline 17 & Domperidome & A03FA03 & 13 & 8.165829146 & 1.641395329 \\
\hline 18 & Insulin lispro & A10AB04 & 5 & 7.851758794 & 1.578264739 \\
\hline 19 & Glibenclamid 5 & A10BB01 & 24 & 7.537688442 & 1.51513415 \\
\hline 20 & L methyl folate & B03BB51 & 12 & 7.537688442 & 1.51513415 \\
\hline 21 & Mecobalamin & B03BA05 & 12 & 7.537688442 & 1.51513415 \\
\hline 22 & Atorvastatin 10 & C10AA05 & 21 & 6.595477387 & 1.325742381 \\
\hline 23 & Sitagliptin 50 & A10BH01 & 20 & 6.281407035 & 1.262611791 \\
\hline 24 & Rosuvastatin 10 & C10AA07 & 9 & 5.653266332 & 1.136350612 \\
\hline 25 & Pyridoxin & A11HA02 & 57 & 5.594378141 & 1.124513627 \\
\hline 26 & Folic acid & B03BB01 & 59 & 5.559045226 & 1.117411435 \\
\hline 27 & Insulin glargine & A10AE04 & 4 & 5.464824121 & 1.098472258 \\
\hline 28 & Pioglitazon 15 & A10BG03 & 16 & 5.025125628 & 1.010089433 \\
\hline 29 & Voglibose 0.2 & A10BF03 & 20 & 4.18760469 & 0.841741194 \\
\hline 30 & Cilinidipin 10 & C08CA14 & 6 & 3.768844221 & 0.757567075 \\
\hline 31 & Gliclazid 40 & A10BB09 & 9 & 3.768844221 & 0.757567075 \\
\hline 32 & Empagliflozin & A10BK03 & 4 & 3.589375449 & 0.721492452 \\
\hline 33 & Linagliptin 2.5 & A10BH05 & 11 & 3.454773869 & 0.694436485 \\
\hline 34 & Linagliptin 5 & A10BH05 & 5 & 3.140703518 & 0.631305896 \\
\hline 35 & Nabivolol 5 & C07AB12 & 5 & 3.140703518 & 0.631305896 \\
\hline 36 & Glimepirid 3 & A10BB12 & 3 & 2.826633166 & 0.568175306 \\
\hline 37 & Rosuvastatin 5 & C10AA07 & 9 & 2.826633166 & 0.568175306 \\
\hline \multirow[t]{2}{*}{38} & Atorvastatin 80 & C10AA05 & 1 & 2.512562814 & 0.505044717 \\
\hline & & & & & $\begin{array}{l}\text { (DU 90\%) } \\
90.37824054\end{array}$ \\
\hline
\end{tabular}

ATC code: Anatomical therapeutic chemical code.

Not a single drug was prescribed by generic name; all the drugs were prescribed by brand name only. $20.43 \%$ of drugs were prescribed from the essential drug list (EDL). Total 93 drugs were studied in drug utilization study for type-2-DM management. DDD/1000/day and DDD\% were calculated for all these drugs. We achieved DU90\% with 38 drugs out of them (Table 3). Vildagliptin, teneligliptin, sitagliptin, and linagliptin are the DPP-4 inhibitor drugs and all of them with certain doses were the part of DU90\% as mentioned in Table 3. Sitagliptin 100 $\mathrm{mg}$ and teneligliptin $10 \mathrm{mg}$ were least prescribed and did not come under the DU $90 \%$ of type-2-diabetes.

\section{DISCUSSION}

Rational drug utilization and efficient drug control system are demanded everywhere in health system without exception to any rule. ATC/DDD is the international standards classification system. Along with the ATC/DDD methodology introduction, it is important that 
its proper use, awareness with timely exploitations inevitably includes an essential step. ${ }^{2}$ With this realization and based on available resources; a small scale, basic observational study was conducted on 199 type-2-DM patients. In the pre-screening, the high number of patients (233) was potentially eligible but the reason for nonparticipation for some of the patients was no willingness to share the prescription, not willing to sign the ICD \& not having much time for conversation.

The drugs like dutasteride and iron ascorbate are neither having DDD and nor having ATC code. They are prescribed to only one patient each and are not included in DDD calculations. DPP-4 inhibitor like teneligliptin 20, which is very new and isn't allotted ATC code and DDD, it is prescribed frequently and is included in analysis. For such frequently prescribed drugs, the DDD should be taken. $^{8}$

After metformin the second most commonly prescribed drug was cholecalciferol i.e. of vitamin D. There is a hypothesis to suggest an association of vitamin D deficiency and diabetes. The destruction of beta cells in the endocrine pancreas is associated with a high level of circulating immune markers, vitamin D act as important immunosuppressive drug hence may take better care of beta cells. ${ }^{9}$ Secondly, vitamin D is related to calcium absorption. In the deficiency of vitamin D, low levels of calcium are observed. Calcium is very important ion for the release of insulin from the beta cell of the pancreas. There are many independent studies to suggest the role of vitamin $\mathrm{D}$ in diabetes. The role is related to good glycaemic control and to reduce insulin resistance. On the other hand, many isolated studies are contradictory to this finding. This hypothesis should be rejected as a metaanalysis of the clinical trial-related to vitamin $\mathrm{D}$ and diabetes clearly state that there is insufficient evidence to support the hypothesis. Clinical usefulness of vitamin D in terms of glycaemic control or insulin resistance is questioned. $^{10}$

Amongst anti-diabetic drugs, biguanides thereafter sulfonylurea and DPP-4 inhibitors are highly prescribed drugs. It shows a close similarity of already published data related to the treatment of diabetes, especially in type-2-DM. ${ }^{11}$ Vildagliptin $50 \mathrm{mg}$ a DDP-4 inhibitor is comparatively more prescribed than the Glimepiride 1mg which is from sulfonylurea group. Clinical trials and some systematic review and meta-analysis also suggest the benefit of use of this drug from the new group in diabetes management with low adverse drug reaction profile. ${ }^{12,13}$ Here it is important to note that vildagliptin in shortacting hence in many patients were prescribed twice whereas linagliptin is long-acting, the once-daily dose is sufficient. Acceptability of DPP-4 inhibitors is very good with very small adverse drug reaction profile. ${ }^{14}$ Teneligliptin is also found to be safe and effective in a large study known as TREAT-INDIA study. ${ }^{15}$
Folic acid and pyridoxine are also prescribed in good amount, this is related to the prevention and treatment of diabetic neuropathy which is common complication observed in diabetic patients. ${ }^{16}$ It was noted that patients receiving only anti-diabetics were $57.77 \%$, coprescription of antidiabetics with cardiovascular drugs were noted in $22.6 \%$ cases. This co-morbidity of diabetes with cardiovascular diseases is well established and reported by many. ${ }^{17}$ Also from the prescribing indices, fewer drugs from essential drug list and less generic prescriptions were observed in many drug use pattern study. ${ }^{18}$

\section{Limitations}

This study included patients from the single site only; that was the private healthcare clinic of an endocrinologist. So, available patients of type-2-DM having comorbidity conditions of cardiovascular diseases and thyroid disorders only. The results generalization to larger or certain kind of population may not much justify.

\section{CONCLUSION}

DPP-4 Inhibitors are the part of drug utilization DU90\% in type-2-DM. This study suggests DPP-4 Inhibitors are having wide acceptability by endocrinologists for type-2DM management. The study concludes that a large number of drugs is in the DU90\% segment with less prescribed drugs from EDL and lack of generic prescriptions. Therefore performing repetitive drug utilization pattern study and circulation of standard treatment guidelines to practising physicians can be required. To emphasize the point on generic prescription, more awareness should be created. So that these can responses to further cost-effective and rational prescribing practices.

\section{ACKNOWLEDGEMENTS}

We would like to thank all the participants and the patients for being part of this study.

\section{Funding: No funding sources}

Conflict of interest: None declared

Ethical approval: The study was approved by the Institutional Ethics Committee

\section{REFERENCES}

1. Pradhan SC, Shewade DG, Shashindran CH, Bapna JS. Drug utilization studies. The National Medical J India 1988;1(4):185-9.

2. World Health Organization. Introduction to drug utilization research. Printed in Oslo, Norway, 2003:33-41. Available at https://apps.who.int/ medicinedocs/en/d/Js4876e/. Accessed on 3 June 2019.

3. Insulin, Oral Hypoglycemic Drugs and Glucagon: Hormones and Related Drugs. In: KD Tripathi. 
Essentials of Medical Pharmacology. 7th ed. Jaypee Brothers Medical Publishers (P) Ltd; 2013;5(19):25882 .

4. Gupta V, Kalra S. Choosing a Gliptin. Indian J Endocrinol Metabol. 2011;15(4):298-308.

5. Powers AC, D'Alessio D. Endocrine Pancreas and Pharmacotherapy of Diabetes Mellitus and Hypoglycemia. In: Brunton LB, Lazo JS, Parker KL, eds. Goodman \& Gilman's The Pharmacological Basis of Therapeutics. 11th ed. New York, NY: McGraw-Hill; 2005.

6. Detournay B, Halimi S, Robert J, Deschaseaux C, Dejager S. Hypoglycemia hospitalization frequency in patients with type 2 diabetes mellitus: a comparison of dipeptidyl peptidase 4 inhibitors and insulin secretagogues using the French health insurance database. Vascular Health Risk Manag. 2015;11:417-25.

7. Montillaa S, Marchesinib G, Sammarcoa A, Trottaa MP, Sivieroa PD, Tominoa C, et al. Drug utilization, safety, and effectiveness of exenatide, sitagliptin, and vildagliptin for type 2 diabetes in the real world: Data from the Italian AIFA Anti-diabetics Monitoring Registry. Nutrition, Metabolism Cardiovascular Diseases; Elsevier. 2014;24:1346-53.

8. WHO Collaborating Centre for Drug Statistics Methodology. Guidelines for ATC classification and DDD assignment. 22nd ed. 2019. Available at https://www.whocc.no. Accessed on 3 July 2019.

9. Pedicino D, Liuzzo G, Trotta F, Giglio AF, Giubilato $\mathrm{S}$, Martini $\mathrm{F}$, et al. Adaptive Immunity, Inflammation, and Cardiovascular Complications in Type 1 and Type 2 Diabetes Mellitus. Hindawi Publishing Corporation J Diabetes Res. 2013;184258:11.

10. George PS, Pearson ER, Witham MD. Effect of vitamin D supplementation on glycaemic control and insulin resistance: a systematic review and metaanalysis. Diabet Med. 2012;29:e142-e150.

11. Luigi B, Julie K. Management of Type- 2 diabetes mellitus in Adults, Focus on individualizing non- insulin therapies. J Pharma Therap. 2012;37(12):68796.

12. Ahren Bo. Use of DPP-4 inhibitors in type 2 diabetes: focus on sitagliptin. J Diabetes Metabol Syndrome Obesity. 2010;3:31-41.

13. Mishriky BM, Cummings DM, Tenenberg RJ. The efficacy and safety of DPP4 inhibitors compared to Sulfonylureas as add-on therapy to metformin in patients with Type 2 diabetes: A systematic review and meta-analysis. J Diabetes Res Clin Pract. 2015;109(2):378-88.

14. Foroutan N, Muratov S and Levine M. Safety and efficacy of dipeptidyl peptidase-4 inhibitors vs sulfonylurea in metformin-based combination therapy for type 2 diabetes mellitus: Systematic review and meta-analysis. Clin Investigative Med. 2016:39(2):48-62.

15. Ghosh S, Trivedi S, Sanyal D, Modi KD, Kharb S. Teneligliptin real-world efficacy assessment of type 2 diabetes mellitus patients in India (TREAT-INDIA study). J Diabetes, Metabol Syndrome Obesity: Targets Therapy. 2016:8(9):347-53.

16. McCann VJ, Davis RE. Pyridoxine and diabetic neuropathy: a double-blind controlled study. J Diabetic Care. 1983;6(1):102-3.

17. Grundy SM, Benjamin IJ, Burke GL, Chait A, Eckel RH, Howard BV, et al. Diabetes and Cardiovascular Disease A Statement for Healthcare Professionals From the American Heart Association. AHA Scientific Statement; 1999;100:1134-46.

18. World Health Organization. The selection and use of essential medicines. World Health Organ Tech Rep Ser. 2014;(985):1-219.

Cite this article as: Shivgunde PP, Joshi SR, Kodilkar AD. The observational, cross-sectional study of drug utilization $90 \%$ and use of dipeptidyl peptidase- 4 inhibitor in the patients with type 2 diabetes mellitus. Int J Basic Clin Pharmacol 2019;8:2376-82. 